\title{
Contradições da Soberania: O Paradoxo da Lógica Intergovernamental da Integração Europeia à Luz do Caso do Sistema Comum de Asilo
}

\author{
Gabriele de Angelis* \\ * IFILNOVA - Instituto de Filosofia da NOVA, Portugal; gabriele@fcsh.unl.pt
}

\begin{abstract}
Resumo
O debate sobre o futuro das reformas da governança europeia versa sobre três questões principais: o problema da finalité, ou seja os objetivos do processo de integração; a repartição das competências entre instituições comunitárias e estados membros; e as formas de participação, diferenciadas de acordo com os interesses dos países membros. Tais questões refletem um diagnóstico acerca dos impasses no processo de integração que sublinha a dificuldade de reconciliar as diferenças sociais e de cultura política, que caracterizam uma União de 27 países, com o nível de integração política e institucional que a multiplicidade de competências legislativas da União requer. Tomando o caso das reformas do Sistema Europeu Comum de Asilo como exemplo ilustrativo, o presente artigo propõe uma interpretação diferente dos impasses institucionais que resultam do modelo "regulatório" de integração até agora perseguido. Tal modelo, inicialmente instituído para que os estados membros mantivessem o controlo sobre o processo de integração, acaba por resultar, pelo contrário, num conjunto de limitações tanto da autonomia política dos estados membros, como da legitimidade política da própria União. Os limites intrínsecos do modelo ficam patentes sobretudo nas áreas de policy onde a eficácia da governança requer a institucionalização duma corresponsabilidade dos estados membros na gestão de problemas comuns, com efeitos na redistribuição de recursos.
\end{abstract}

Palavras-chave: legitimidade política; modelo regulatório; reformas da governança; Sistema Europeu Comum de Asilo; soberania; Teoria dos bens públicos 


\begin{abstract}
The debate about the future of European governance revolves around three main questions: the finalité, i.e. the overall goals of integration; the attribution of competences between EU institutions and the member states; and differentiated integration. These questions rest on a diagnosis of the European malaise that highlights the clash between widening and deepening, i.e. the difficulty of reconciling the social, cultural, and political diversity within the Union of 27, and the degree of shared sovereignty that is required in order to properly manage the multifarious EU competences. Illustrating the case of the Common European Asylum System (CEAS) and its far failed reform, the present contribution suggests a different interpretation of the institutional impasse that currently beset the EU. Such impasse results from the ongoing pursuit of a regulatory model of governance. Despite being meant to allow member states to keep control over the integration process, such a model results, instead, in a number of unintended constraints on member states' political autonomy. Additionally, it also undermines the Union's political legitimacy. The limits of the model become patent whenever common policy areas have redistributive implications. In these cases, of which the CEAS is a chief example, efficiency and joint responsibility for the achievement of common purposes go hand in hand. Focused on the prevention of externalities, the regulatory model is unable to solve the collective action problems that arise in such policy areas.
\end{abstract}

Keywords: Common European Asylum System; governance reforms; political legitimacy; public goods approach; regulatory mode; sovereignty

\title{
1. Introdução
}

Com o objetivo de estimular o debate público sobre o futuro da União, a Comissão Europeia difundiu, em 2017, um conjunto de documentos (incluindo o White Paper on the Future of Europe, o Reflection Paper on Harnessing Globalisation, etc.) (Comissão Europeia, 2017a; 2017b) que ilustram as hipóteses de alteração da arquitetura institucional da polity europeia. Três são os seus aspetos fulcrais:

1a. A assim chamada finalité, ou seja, os objetivos fundamentais que a União persegue e que são o pressuposto político da sua articulação;

2a. A definição das suas competências em relação ao espaço de soberania dos estados membros;

3a. Os termos de participação nas áreas de competência da União, que podem vir a ser diferenciados consoante forem os interesses específicos dos estados membros.

Com isso, a Comissão reconhece três falhas políticas, correspondentes aos três pontos acima mencionados:

1b. Uma persistente divergência entre os estados membros acerca dos objetivos "últimos" do processo de integração, à qual corresponde uma diversidade de interesses no desenvolvimento do próprio processo, nomeadamente entre os 
Estados que privilegiam a dimensão do mercado único e os que visam alcançar uma integração multidimensional que possa abranger, por exemplo, as políticas de segurança e defesa, energética, ambiental, etc.;

2b. Uma consequente resistência à extensão das competências da União a âmbitos políticos que, na visão das autoridades ou dos atores políticos nacionais, pertencem à soberania exclusiva do Estado ou às liberdades dos atores sociais nacionais, o que pode vir a incluir limitações à interpretação das "quatro liberdades" (de circulação de pessoas, capitais, bens e serviços), nas quais assenta o mercado único;

3b. A consequente necessidade de diferenciar os termos da participação de forma a acautelar a funcionalidade das instituições e garantir o avanço do processo para quem quiser estender a abrangência da integração em termos de âmbitos de policy.

Às três falhas políticas correspondem três falhas institucionais, nomeadamente:

1c. Um impasse no seio do Conselho Europeu na tomada de decisões, em particular no que diz respeito aos âmbitos de policy sobre os quais não existe consenso a respeito das competências, o que é bem ilustrado pelas divergências sobre as políticas migratórias;

2c. O défice de legitimidade apontado pelos atores sociais e políticos que, perante decisões supranacionais, experimentam a insuficiência da dimensão política nacional;

3c. A dificuldade da União em produzir uma oferta política satisfatória em termos de capacidade de ação, resolução de conflitos e produção de bens públicos, ou seja: uma falta de deliverance, da qual o escasso progresso das reformas da União Económica e Monetária e do Sistema Comum de Asilo são dois exemplos gritantes.

Os documentos da Comissão são um importante ponto de partida para os atuais debates sobre o futuro da polity europeia. É, todavia, questionável se o diagnóstico identifica corretamente o problema que atinge as instituições da União. Na perspetiva da Comissão, o problema consiste na tensão existente entre deepening e widening, ou seja, entre a diversidade de interesses e objetivos que resulta da dimensão geográfica, e com isso da diversidade social, histórica e política, da União, e a sua capacidade de obter o grau de "profundidade" de integração suficiente para gerir as competências adquiridas. Por isso, alterar, e eventualmente reduzir as competências ou diferenciar as agregações seria a solução mais consequente.

Contudo, os impasses das reformas da zona euro, ou seja da área mas estritamente integrada, e do Sistema Comum de Asilo, ou seja, da área atualmente mais controversa no seio da União, não parecem confirmar a hipótese da Comissão. Embora seja evidente que as duas áreas mostram problemas que se relacionam com a diversidade 
dos seus membros - de produtividade e de "modelo social" (Dørvik e Martin, 2017), a primeira, e de atitude das autoridades perante o fenómeno migratório em geral, a segunda (V4, 2017) —, é também evidente que restaurar a homogeneidade dos países participantes não seria uma solução viável no caso da UEM, que teria de enfrentar as consequências do break-up do euro. Uma participação diferenciada seria, pelo contrário, teoricamente possível no caso do Sistema Comum de Asilo. Contudo, as divisões políticas atravessam as diferentes áreas geográficas da União, com divergências transversais a qualquer divisão político-geográfica menos que aleatória, como o demonstram o caso da Áustria (contrária às reformas tout court), a mudança de rumo da Alemanha na gestão dos fluxos balcânicos, a mudança de rumo da Itália em relação ao fluxo mediterrânico e, com algumas diferenciações, o conflito entre França e Itália na gestão da crise líbia e dos consequentes fluxos daquele país. Nesse sentido, os ditos impasses permitem aventar uma hipótese diferente.

\section{O Diagnóstico das Falhas Institucionais da União}

A hipótese que se pretende discutir é a seguinte: os impasses que caracterizam a fase atual do processo de integração são uma consequência dum sistema de governança concebido com o propósito de constituir a União enquanto "entidade reguladora" (Majone, 1998; 2005), ou seja como uma entidade que gere a produção de diferentes bens públicos, tais como a segurança, a gestão das fronteiras, a inflação agregada, etc., distribuindo os relativos "custos de produção" entre os países membros duma forma que estes possam controlar. O sistema é concebido de forma a garantir um alto nível de consentimento na tomada de decisões, assim que nenhum estado membro se sujeite, na medida do possível, à vontade de outrem. Embora tal forma de governança tenha sido alterada, ao longo do tempo, no sentido de enfraquecer a original condição de unanimidade no que diz respeito a cada vez mais áreas legislativas (Grimm, 2017) (e excluindo as áreas de grande importância da UEM, cujas regras fundamentais são parte dos tratados e, por isso, sujeita à unanimidade), o nível de consentimento requerido entre e dentro das instituições comunitárias é ainda notável, não só por causa da possibilidade de minorias de bloco, mas também por causa do papel do Conselho Europeu na determinação do percurso e da iniciativa legislativa.

Embora o princípio da decisão consensual nascesse como garantia contra a heteronomia política dos estados membros, o resultado pode, de facto, vir a ser o oposto, na medida em que as decisões tomadas no suposto interesse equitativo de todos os estados membros produzem consequências iníquas. É o caso do Sistema Comum de Asilo, que determina uma repartição desigual do peso económico, político e social da receção e assistência de refugiados, assim como uma gestão assimétrica dos fluxos migratórios. Num tal caso, as assimetrias determinam um interesse correspondentemente desigual na alteração das regras e uma consequente dificuldade em proceder às reformas, em virtude da exigência de uma unanimidade de facto, não obstante se trate duma área à qual se aplica o procedimento legislativo ordinário. 
Por outro lado, a dificuldade em conseguir uma gestão comum e consensual de âmbitos importantes de policy acarreta um conjunto de efeitos colaterais, devidos, mais uma vez, às características do sistema institucional.

Para além dos problemas de equidade acima mencionados, o primeiro efeito colateral é uma crise de confiança entre estados membros, em caso de crises. As políticas da União são levadas a cabo pelas instituições e autoridades nacionais. À divergência dos interesses nacionais corresponde um divergente interesse em implementar as normas comuns. Por conseguinte, os Estados podem bem desconfiar da efetiva vontade dos parceiros em implementar as normas, como o demonstram os conflitos na gestão das fronteiras entre Itália e Áustria, Itália e França e, em geral, as recentes interrupções temporárias na implementação do Tratado de Schengen (Comissão Europeia, 20161).

O segundo é um problema de legitimidade política da ação dos governos nacionais perante o próprio eleitorado. Enquanto o ónus da implementação das regras europeias por parte das autoridades nacionais recai sobre os cidadãos nacionais, as agências da representação política não têm jurisdição exclusiva sobre a matéria, embora mantenham a responsabilidade política perante os próprios cidadãos. Cria-se, assim, um vazio político, enquanto um legítimo interesse dos cidadãos nacionais não possa ser satisfeito, não obstante a repartição do ónus lhes possa ser desfavorável. $\mathrm{O}$ paradoxo da construção europeia é, portanto, o seguinte: instituições construídas para preservar a integridade da soberania e das liberdades nacionais acabam por minar os princípios que visavam proteger.

Pergunta-se, então, que alterações à construção institucional europeia permitiriam ultrapassar o impasse institucional. Mantendo firme a resolução de privilegiar a soberania e as liberdades dos cidadãos nacionais, tanto a Comissão Europeia quanto os legisladores escolheram transferir para a União algumas competências soberanas, o que inclui a constituição de agências europeias com, em alguns casos, poder operacional direto. Contudo, a solução escolhida não resolve os problemas de legitimidade e equidade, e só com muita dificuldade poderá resolver o problema da eficácia.

O primeiro objetivo que este artigo pretende cumprir é o de mostrar porque é que as soluções dos legisladores não resolvem os três problemas em questão e por que razão o impasse principal reside, principalmente, na própria lógica intergovernamental do processo de integração.

O segundo objetivo que este artigo pretende cumprir é a de indicar por que razão o impasse não é de natureza extemporânea, mas tem as suas raízes no modelo regulatório de integração.

Para circunscrever o âmbito da matéria, escolher-se-á o exemplo do Sistema Comum de Asilo. 


\section{O Sistema Europeu Comum de Asilo: Razões duma Crise}

O Sistema Europeu Comum de Asilo (SECA) consiste num conjunto de Regulamentos e Diretivas que visam constituir um quadro legal comum na gestão do direito de asilo. Em particular, o SECA pretende determinar qual dos estados membros tem a responsabilidade de processar os pedidos de proteção internacional (Regulamento (EU) N. 604/2013 - "Dublin III"), harmonizar os procedimentos de atribuição do estatuto de proteção internacional (Diretiva 2013/32/EU), determinar os padrões mínimos comuns de acolhimento e assistência aos requerentes de proteção internacional (Diretiva 2013/33/EU), e os padrões que determinam o direito ao reconhecimento de tal estatuto (Diretiva 2011/95/EU).

O consistente aumento nos fluxos de requerentes de asilo que se verificou a partir de 2015 revelou uma falha na construção do SECA e, especialmente, do "Dublin III", o qual atribui a responsabilidade de processar o pedido de asilo ao estado onde a pessoa requerente chega primeiro, independentemente do local onde esta deseja registar o seu pedido. Um tal Regulamento, embora conforme à lei internacional, pressupõe tanto um eficaz controlo das fronteiras internas e externas do estado em questão, quanto a existência de acordos eficazes de gestão dos fluxos com os países terceiros que a pessoa requerente atravessa. Caso estas condições não se cumpram, os estados cujas fronteiras terrestres ou marítimas se encontrarem mais expostas aos fluxos serão encarregues de processar a grande parte dos pedidos, assim como de garantir o acolhimento e a assistência. Foi este o caso que se verificou a partir de 2015 com os países mediterrânicos, e especialmente a Grécia, Itália e Malta (European Parliament Research Service, 2016). O Regulamente de Dublin resultou, portanto, numa repartição desigual dos custos políticos e económicos do acolhimento de requerentes de asilo.

Uma consequência ulterior de tal repartição foi uma suspensão de facto e, temporária e limitadamente, também de jure, da aplicação do Regulamento, que ocorreu quando os estados em questão, especialmente Itália e Grécia, deixaram de conseguir ou de querer dar seguimento à obrigação de registar as pessoas requerentes de asilo que, em trânsito para outros países membros, teriam que ser re-acompanhadas ao país da primeira chegada (Comissão Europeia, 2016a).

Às falhas do Regulamento juntaram-se algumas falhas nas Diretivas que completam o SECA. A implementação discricional ou incompleta das Diretivas por parte dos países membros levou a um diferente tratamento das pessoas requerentes de asilo, nomeadamente em termos de duração do processamento dos pedidos, dos seus êxitos, ou das condições de acolhimento, determinando assim um interesse por parte dos requerentes em escolher os países mais "generosos" e um correspondente fluxo de "movimentos secundários", que o Regulamento de Dublin, formalmente, não admite (Comissão Europeia, 2016d). Aumentou, portanto, o interesse em restaurar os controlos de fronteiras que o Regulamento de Schengen deveria, em princípio, eliminar (Comissão Europeia, 2016b). 
Perante um fenómeno crítico pelas suas proporções e inesperado nas suas dinâmicas repentinas, as assimetrias produzidas pelo SECA conduziram a uma situação de iniquidade e desconfiança entre os países membros, pondo em risco outras instituições fulcrais da União, nomeadamente a implementação do princípio de livre circulação de cidadãos.

Tais consequências mostraram, ao mesmo tempo, outra fraqueza ínsita nas características institucionais da União. A União, considerada uma instituição sui generis que reúne características tanto dum estado federal como duma organização internacional (Phelan, 2012), distingue-se do primeiro por dois elementos fundamentais: o facto dos estados membros deterem a competência exclusiva de legislação primária por acordo internacional unânime, e o facto de a legislação da União ser implementada unicamente por autoridades nacionais, vigiadas, por delegação dos próprios estados membros, por um organismo técnico tal como a Comissão. O interesse na adequada implementação varia, compreensivelmente, com a variação dos custos, políticos ou económicos, que resultam para estados membros. Em caso de interesse fortemente desigual, a desconfiança na atuação dos parceiros europeus é a lógica consequência duma tal repartição de competências, ou seja da própria estrutura institucional que os estados membros quiseram atribuir à União no intento de manter nas suas próprias mãos as rédeas do processo de integração (Moravcsik, 1997, 1998).

Na mesma lógica, a medida mais imediata que permitisse restaurar a confiança e a capacidade de coordenação perdidas consistiria numa mais estrita vigilância sobre a correta implementação das regras. É, contudo, evidente que o problema de implementação é somente uma consequência do "desenho" errado das próprias regras que, contrariamente às intenções que as originaram, determinam um conjunto de assimetrias e de interesses desiguais dos estados membros. Por admissão da Comissão (2016c, p. 4), o Regulamento de Dublin não visava estruturar o SECA como um instrumento apto a enfrentar problemas comuns de dimensão global numa lógica de corresponsabilidade. Pelo contrário, o Regulamento visava desencorajar um controlo lasso das fronteiras por parte dos países membros, fortalecendo assim a sua autorresponsabilidade, que teriam de enfrentar sozinhos as consequências da própria negligência, e protegendo, com isso, os restantes das eventuais falhas dos parceiros. A harmonização do sistema de asilo visava cumprir a mesma função através da criação dum level playing field (Comissão Europeia, 2016c, p. 7) entre os países membros, de forma que as condições desiguais de tratamento de requerentes de asilo não constituíssem um fator de atração ( $p$ ull factor), encorajando a escolha dum país por causa das melhores condições oferecidas.

Em outras palavras, o SECA tinha sido estruturado como um sistema de regras que visavam proteger o conjunto de estados das externalidades produzidas pelo comportamento impróprio dos outros membros da comunidade numa lógica de prevenção do "parasitismo" (Olson, 1971), ou seja, da atitude de quem aproveita um bem público (ou seja um bem cujo usufruto, pelas próprias características do bem, não 
pode ser limitado a quem o produz), sem querer partilhar os custos da sua produção. O bem público em questão é a livre circulação dentro das fronteiras da União (Comissão Europeia, 20161), assim como a segurança que é preciso garantir para que tal liberdade seja preservada (Thielemann, 2018, p. 64; Thielemann \& Armstrong, 2013, p. 154). O risco de parasitismo provém da certeza de que o prejuízo causado por um controlo impróprio das fronteiras externas seria partilhado e, por isso, diluído por todos os parceiros.

Acontece, assim, o choque entre duas lógicas diferentes de estruturação de regras comuns: a lógica regulatória (Majone, 2005, pp. 33-35), motivada pela prevenção de externalidades, contra a lógica da corresponsabilidade e mutualidade de esforços perante riscos comuns. Neste choque, e nos divergentes interesses dos estados membros, reside a origem do atual impasse nas reformas do SECA.

Consciente da diferença profunda entre as duas opções, a própria Comissão propôs reformas que se enquadrassem alternativamente numa das duas lógicas, assim permitindo que os estados membros pudessem orientar as suas ações num sentido ou no outro, consoante for a escolha do rumo a dar ao desenvolvimento do SECA e, com isso, a uma porção consistente da Área da Justiça e dos Assuntos Internos.

\section{As Reformas do SECA}

Dum ponto de vista teórico, as dificuldades acima mencionadas na gestão dos fluxos de requerentes de asilo constituem um problema de ação coletiva, que surge quando os atores têm interesse em minimizar a própria participação nos custos de produção dum bem público por motivos de racionalidade individual, ou então receiem entrar num regime de colaboração por motivos de desconfiança nos coatores, mesmo que a consequência seja a não-produção do bem em questão, que é, no entanto, do interesse de todos (Olson, 1971). Uma solução para tal problema é conhecida desde o início do pensamento político moderno, e consiste em atribuir a uma autoridade comum o poder direto de coordenar as ações dos coatores, assim como de aplicar as devidas sanções aos comportamentos divergentes [Hobbes, (1651) 2012; Kant, (1795) 1991].

Tal solução admite diferentes implementações: desde a formação dum estado, se a autoridade em questão for equipada com o monopólio do uso legítimo da força (Weber, 1946), até à formação duma agência com poder delegado de coordenar a ação dos coatores e/ou atuar em primeira pessoa, assim como de aplicar sanções que vão até à exclusão do consórcio de produção do bem público (Buchanan, 1965), sem monopólio, ou, como no caso da UE, sem uso da força tout court.

De facto, as propostas da Comissão (2016e, 2016f, 2016g, 2016h, 2016i, 2016j) visavam corrigir a insuficiente coordenação das ações dos estados membros nas políticas de acolhimento de pessoas refugiadas através de dois tipos de medidas.

Por um lado, tratava-se de confirmar a lógica do level playing field (garantindo igualdade de tratamento das pessoas refugiadas) e de prevenção de externalidades (garantindo a eficácia da ação dos estados membros através dum mais estrito controlo tanto dos movimentos secundários, quanto das fronteiras). 
Por outro lado, tratava-se de resolver os problemas de iniquidade na distribuição do peso do acolhimento, preconizando assim uma lógica de partilha de responsabilidades. Ambos os objetivos sujeitam-se à mesma condição de viabilidade: que a entidade coordenadora seja eficaz.

O reforço das condições de coordenação da ação passava, justamente, pela atribuição dum maior papel às instituições comunitárias, nomeadamente através duma nova agência europeia que resultasse dum mais abrangente mandato do European Asylum Support Office (EASO) e que pudesse, a longo prazo, centralizar os procedimentos de atribuição do estatuto de refugiado (Comissão Europeia, 2016c, p. 7-9).

O papel da Guarda Europeia de Fronteiras e Costeira (GEFC), que continua sob a designação de FRONTEX e que desempenhará uma função “operacional”, e não somente de acompanhamento e monitorização, no patrulhamento das fronteiras marítimas, vai na mesma direção de garantir que a receção de pessoas refugiadas corresponda aos padrões do renovado SECA, aliviando, no mesmo tempo, o peso que cabia ao estado fronteiriço no desempenho desta tarefa (Comissão Europeia, 2015 , p. 3). Esta é, até agora, a única proposta de reforma que chegou com sucesso ao fim do percurso legislativo [Regulamento (UE) 2016/1624].

Finalmente, uma ulterior proposta, que também implicava uma mudança de rumo na gestão dos problemas de ação coletiva dentro da União, dizia respeito à dimensão da "solidariedade" no acolhimento de pessoas refugiadas. Tal proposta consistia num mecanismo de distribuição "automático" que deveria ativar-se em presença de certas condições. "Automático" significa que o seu funcionamento não depende de acordos ad hoc entre os estados membros, mas é promovido pela Comissão ou pelo renovado EASO, constituindo uma obrigação contratual entre os estados que as instituições supranacionais têm o papel de implementar.

Esta última proposta coincidia com uma mudança na lógica do SECA, que passaria a incluir, a par da manutenção dum level playing field e da prevenção do parasitismo, uma lógica de partilha de responsabilidade num contexto ético de equidade. Significativamente, a Comissão (2016h, p. 2) reconhece a interligação entre os dois aspetos do problema da ação coletiva, ou seja a ineficácia dum sistema iníquo. $\mathrm{O}$ facto de uma tal mudança na lógica de Dublin ser associada ao reforço das correspondentes instituições supranacionais que coordenem as ações dos estados membros de uma forma mais ativa em relação à situação atual, ou seja, com mais poder de coordenação, ação direta e sanção, é de importância fundamental, pois explicará (na última secção do presente artigo) as razões práticas e políticas que dificultam o processo de reforma da União, e, especialmente, do SECA. Esta última proposta (doravante: "Dublin recast"), que visava reformar o "Sistema Dublin III", e a instituição da GEFC merecem uma atenção particular. 


\section{A Difícil Tarefa de Conservar a Soberania através da Cedência de Soberania}

Coerentemente com o objetivo de resolver o problema de ação coletiva que aflige o SECA, tanto a "Dublin recast", quanto a nova GEFC, caracterizam-se pelas limitações que impõem à soberania dos estados membros.

Em primeiro lugar, uma tal limitação manifesta-se nas medidas de reforço da prevenção de externalidades, que se focalizam sobre a execução a mais automática possível do princípio do "único estado responsável" pelo pedido e o acolhimento da pessoa refugiada. Por exemplo, uma "notificação de retoma" deveria substituir o "pedido de retoma" no caso de movimentos secundários não autorizados (2016h, p. 16). Mais significativo é, todavia, o "mecanismo corretivo", que deveria levar a uma partilha de responsabilidade no acolhimento de pessoas refugiadas.

Tal mecanismo prevê uma redistribuição de requerentes de asilo baseada num cálculo que considera, com ponderação igualitária, a dimensão do PIB e da população, de forma a construir uma chave de repartição que determine o peso relativo do acolhimento a suportar pelos países membros. Tal chave aplicar-se-ia no caso em que um ou mais países sejam sujeitos a uma "pressão desproporcionada", ou seja igual a $150 \%$ do valor medido nos termos da mesma chave, e determinaria uma recolocação de requerentes de asilo para os países que denunciam um número inferior, sempre em relação à dita chave (Comissão Europeia, 2016h, pp. 18-19, 28-30). Os países membros podem recusar a aplicação do "mecanismo corretivo" durante um período de doze meses, tendo, mesmo assim, a obrigação de participar nos custos do acolhimento com uma contribuição fixa de $250.000 €$ por cada requerente que deviam ter recebido. O poder de implementação do Regulamento seria atribuído à Comissão (2016h, p. 32).

Note-se que, dos dois mecanismos de realocação que a Comissão avançou inicialmente (2016c, pp. 7-8), no Regulamento a ser debatido foi incluída a proposta com a menor componente de supranacionalização e corresponsabilidade. A Comissão tinha proposto, em alternativa, uma realocação "direta" e independente de situações de emergência.

Significativo é que a supranacionalização de funções e a passagem a uma partilha de responsabilidades aconteça com o objetivo de manter o princípio fundamental de resguardar os estados membros das consequências das políticas dos outros, como demonstra a própria justificação da reforma, que visa limitar os movimentos secundários mantendo a funcionalidade dos sistemas nacionais de acolhimento de pessoas refugiadas. Não é casual que o princípio do "único estado responsável" pelo processamento do pedido e do acolhimento, salvo situações de emergência, ocupe a parte maior das reforma, resultando, aliás, reforçado tanto no "Dublin recast" (2016h, pp. 4-27), quanto nas funções da GEFC.

Também a reforma de FRONTEX persegue a estratégia de fortalecer as capacidades de resposta comum a desafios globais numa lógica de prevenção de externalidades. Para esse efeito, a GEFC desempenha tarefas próprias duma agência supranacional, ou seja de monitorização, informação, troca de boas práticas, suporte 
técnico, etc. A essas funções técnicas associam-se, contudo, funções policiais, seja no controlo das fronteiras, seja na colaboração nos hotspots. A Agência GEFC pode, em particular, decidir autonomamente que subsistem as condições para um reforço do controlo de fronteiras:

Nos casos em que existam desafios desproporcionados e específicos nas fronteiras externas, a Agência deverá, a pedido de um Estado-Membro ou por sua própria iniciativa, organizar e coordenar intervenções rápidas nas fronteiras e destacar equipas europeias de guardas de fronteira e guarda-costeiros de uma reserva de reação rápida, assim como o equipamento técnico [o sublinhado foi acrescentado] (Regulamento (UE) 2016/1624, L 251/19-20).

Não tendo a agência pessoal próprio, senão o que lhe tenha sido disponibilizado pelos estados membros, isto significa que a agência desloca, por sua própria iniciativa, pessoal dos outros estados. Uma tal medida pode assumir caraterísticas de intervenção dos estados membros no controlo das fronteiras externas, independentemente do país ao qual estas pertencem, no caso em que a incapacidade ou falta de vontade do estado membro em questão perante uma situação de pressão prolongada e consistente venha a representar uma ameaça para as fronteiras internas da área Schengen. É, neste caso, o Conselho, por sugestão da Comissão, a decidir sobre as medidas a tomar pela própria Agência:

Nos casos em que o controlo nas fronteiras externas se torne de tal forma ineficaz que ponha em risco o funcionamento do espaço Schengen, porque um determinado Estado-Membro não tomou as medidas necessárias em conformidade com a avaliação da vulnerabilidade, ou, porque, um Estado-Membro que se viu confrontado com desafios desproporcionados específicos nas fronteiras externas não solicitou à Agência apoio suficiente ou não executou esse apoio, uma resposta rápida, unificada e eficaz deverá ser dada, a nível da União. Para atenuar esse risco, e a fim de garantir uma melhor coordenação a nível da União, a Comissão deverá propor ao Conselho uma decisão que identifique as medidas a executar pela Agência e que solicite ao Estado-Membro em causa que coopere com a Agência na aplicação dessas medidas. As competências de execução para a adoção dessa decisão deverão ser conferidas ao Conselho em virtude da natureza potencialmente sensível em termos políticos das medidas a decidir, que provavelmente entram no âmbito dos poderes nacionais executivos e coercitivos. A Agência deverá determinar as medidas a tomar para a execução das medidas indicadas na decisão do Conselho e após elaborar um plano operacional com o Estado-Membro em causa. Caso um Estado-Membro não cumpra a decisão do Conselho num prazo de 30 dias e não coopere com a Agência na execução das medidas que constam na referida decisão, a Comissão deverá poder desencadear a aplicação do processo específico previsto no artigo 29.o do Regulamento (UE) 2016/399 do Parlamento Europeu e do Conselho, para fazer face à situação em que circunstâncias excecionais colocam em risco o funcionamento global da zona sem fronteiras internas. Por conseguinte, o Regulamento (UE) 2016/399 [relativo à gestão das fronteiras de Schengen: o Art. 29 determina, em particular, as condições 
a verificar-se pela suspensão da livre circulação em regime de fronteiras abertas] deverá ser alterado (Regulamento (UE) 2016/1624, L 251/4).

O regulamento persegue, assim, o duplo objetivo de reforçar os recursos para o controlo cooperativo das fronteiras enquanto determina, ao mesmo tempo, as condições que justificam uma ingerência no espaço de soberania dos estados membros numa área "clássica" do poder dos estados, ou seja o poder policial e militar relativo ao controlo das fronteiras. Significativa é, neste contexto, a "condicionalidade" imposta aos países membros relativamente ao direito a participar na área de Schengen, assim como a exclusão dos incumpridores do gozo do bem comum.

Em conclusão, os estados membros mostram interesse em supranacionalizar as funções mínimas necessárias a garantir a funcionalidade do sistema de asilo com o objetivo principal de limitar as externalidades, ou seja, de proteger-se, na medida do possível, das consequências negativas da ação dos parceiros. Só visando este objetivo é que os estados parecem dispostos a aceitar uma lógica de partilha de responsabilidades e, ainda assim, na forma que menor impacto promete em termos de obrigações factuais. Contudo, até para uma de tal forma limitada de corresponsabilidade faltou, até agora, um consenso entre os estados membros.

Foi, pelo contrário, encontrada uma maioria para aprovar as medidas que reforçam o controlo das fronteiras, mesmo que estas impliquem, em excecionais condições de "pressão" dos fluxos migratórios, uma severa limitação do poder autónomo dos estados numa das esferas mais "delicadas" da sua soberania. Notável é, também, que um tal Regulamento tenha sido aprovado sem alguma garantia de equidade e corresponsabilidade na gestão dos fluxos e do acolhimento, ou seja, sem a contextual aprovação daqueles Regulamentos que completariam a "disciplina" do controlo das fronteiras com a "solidariedade" na distribuição dos custos do bem comum.

\section{Conclusão: "Masters of the Treaties" - O Paradoxo da Lógica Intergovernamental}

O diagnóstico até agora desenvolvido leva a reconsiderar criticamente os pressupostos nos quais assenta a análise da Comissão (2017a). De facto, mais do que nas diferentes visões acerca do rumo a dar ao processo de integração por parte dos estados membros (finalité) (1a, 1b), os impasses nas reformas do SECA têm a sua origem na persistente preferência por um modelo regulatório de integração orientado para a prevenção de externalidades.

As competências $(2 \mathrm{a}, 2 \mathrm{~b})$ que os estados membros estão disponíveis para transferir aos órgãos supranacionais são relativas a esta função, e só secundaria e subsidiariamente permitem também uma re-distribuição de recursos. Esta função, aliás, permanece mínima, como demonstra o falhado percurso legislativo da reforma " $\mathrm{Du}$ blin recast".

A diferenciação na participação nas políticas comuns (3a, 3b) aparece, na única reforma de relevo até agora aprovada, relativa à GEFC, como ameaça de exclusão do 
proveito dum bem público no caso de incumprimento das obrigações de controlo das fronteiras. Face à interdependência entre a liberdade de movimento dentro da área de Schengen e a necessidade de controlar os fluxos migratórios, a hipótese duma diferenciação permanente parece, aliás, duvidosa.

Os impasses no processo de reforma (1c) explicam-se em grande medida pela preferência por este modelo de integração. Por meio do poder do Conselho Europeu de determinar a agenda (Chalmers, Davies \& Monti, 2010, pp. 75-78), o modelo regulatório atribui aos estados membros o controlo factual sobre o avanço do processo de integração mesmo naquelas áreas legislativas sujeitas a voto com maioria qualificada. No caso do CEAS, esse poder foi exercido para determinar que o nível de consentimento necessário para avançar com as reformas era, de facto, a unanimidade (Conselho Europeu, 2018). A consensualidade advém do facto das reformas em questão tocarem em funções que pertencem ao núcleo da soberania nacional. Adicionalmente, o problema do acolhimento e da integração de pessoas refugiadas é de natureza tal que não pode prescindir do consentimento dos países acolhedores, pelo que uma decisão por maioria qualificada não teria o efeito esperado de estabilizar a área de Schengen. Finalmente, uma razão ulterior para privilegiar a unanimidade em decisões "sensíveis" consiste na natureza das instituições da União, cujos recursos próprios são escassos e limitados, a uma função técnica de apoio, suporto e monitorização, como convém a uma agência supranacional com função de "agente", cujos “principals” são, novamente, os estados membros (Kassim \& Menon, 2003). Por isso, a Comissão e as agências europeias precisam da colaboração das instituições dos estados membros para que a legislação da União seja implementada.

Tal modelo "regulatório" visa maximizar o controlo sobre o processo de integração por parte dos estados membros. Em princípio, o modelo garante que o processo só avance na condição de que cada membro possa encontrar nas decisões tomadas mais vantagens que desvantagens, parar o progresso de decisões indesejadas e medir a porção de soberania que decide transferir.

É, portanto, paradoxal que este mesmo modelo acabe por constituir uma consistente limitação tanto da soberania dos estados membros, quanto da legitimidade política e da eficácia da integração.

No caso em que a regulação duma área de policy resulte ineficaz (3c), o problema é amplificado pelos impasses no Conselho Europeu. Na medida em que a ineficácia resulta da iniquidade da legislação, como é o caso do SECA, o modelo regulatório dificulta o progresso rumo à necessária partilha de responsabilidades. As próprias regras, formais ou informais, de maioria ou de unanimidade no Conselho Europeu, representam em si uma limitação de soberania para os países que sofrem as consequências maiores da iniquidade da regulação, pois a restauração da equidade necessita do consentimento de todos, enquanto a iniquidade determina um grau diferente de interesse no progresso das reformas. Um estado que, uma vez aprovada a legislação com pleno consentimento, experimente a necessidade de alterá-la, pode encontrar um obstáculo no requerimento da unanimidade de facto. Assim, o que é, 
inicialmente, garantia de consentimento, torna-se eventualmente num obstáculo à autodeterminação.

Cria-se, com isso, um problema de legitimidade, seja pela falta de capacidade de problem solving por parte das instituições europeias devida aos impasses legislativos, seja pela falta de input legitimacy do processo. Uma vez que uma área de policy pertence ao âmbito de competência da União, os representantes políticos nacionais não têm a exclusividade do poder legislativo sobre as suas alterações. Por isso, o eleitorado dos países que mais desejariam uma tal alteração perde a capacidade de influenciar as relativas decisões, sem, por isso, recuperar poder decisional ao nível europeu por insuficiente competência de facto do Parlamento Europeu (o problema da composição do Parlamento, das suas insuficientes ligações com os eleitorados nacionais em termos de comunicação e identidade política, assim como o problema das diferentes leis eleitorais nacionais, serão aqui apenas mencionados; veja-se e.g. Grimm, 2017, Cap. 7).

A assimetria de interesses nas reformas, acima mencionada, manifesta-se plenamente no caso do SECA. Se, por um lado, a reforma do FRONTEX garante aos estados fronteiriços um maior apoio técnico e operacional por parte dos parceiros europeus, através da coordenação da agência GEFC, a reforma reforça o princípio de responsabilidade dos estados fronteiriços e, com isso, a iniquidade da legislação atual de Dublin. Da mesma forma, os estados fronteiriços são os que mais podem correr o risco de serem excluídos da participação na área de Schengen no caso em que, frente a uma pressão migratória excecional, não consigam controlar as fronteiras. No caso extremo em que a GEFC se mobilize por decisão própria ou do Conselho, a gestão das fronteiras nacionais (incluindo, na totalidade ou em parte, a gestão dos acessos, a análise de admissibilidade dos pedidos de asilo, das eventuais detenções provisórias em hotspots, etc.) passa, de facto, para as mãos duma agência que só é responsável perante um órgão intergovernamental [Regulamento (UE) 2016/1624, L 251/7, 13], mesmo que opere junto das fronteiras de um só estado membro.

Da transferência de soberania no quadro "regulatório" advém uma ulterior limitação da legitimidade política do SECA. Dum ponto de vista ético-normativo, o SECA determina um enquadramento específico do problema da gestão dos fluxos de pessoas refugiadas, privilegiando o controlo das fronteiras, ou seja, a limitação aos ingressos, sobre o direito de asilo. Um tal enquadramento do problema levanta questões de constitucionalidade, assim como de interpretação dos valores nos quais se reconhece a polity europeia (Menéndez, 2016, pp. 408-12). Os Regulamentos do SECA determinam, igualmente, um conjunto de políticas de acolhimento que, por causa do patamar da maioria requerida no Conselho para eventuais alterações, são de facto excluídos da competição política e subtraídos ao juízo dos eleitores. Isso inclui a eficácia, ainda a demonstrar, da estratégia na qual assenta a GEFC, ou seja, que o controlo das fronteiras, especialmente as marítimas, seja, de facto, possível.

Em conclusão, o modelo "regulatório" de integração que os estados membros têm, até agora, perseguido, parece ter chegado aos seus limites, seja por causa das 
limitações que a integração, na sua forma atual, impõe à soberania dos estados e aos valores democráticos dos cidadãos europeus, seja pelas próprias contradições no seio do processo, que foi pensado para garantir que os membros mantivessem o controlo sobre os seus avanços, mas que acaba por subtrair, de facto, autonomia decisional aos estados. Isso parece patente nos casos em que, como o do SECA, o processo de integração toque em funções fundamentais da soberania estadual e coloque problemas de justiça distributiva.

Data de receção: 23/03/2019

Data de aprovação: 05/11/2019

\section{Referências}

Buchanan, J.M. (1965). An Economic Theory of Clubs. Economica, 32(1), 1-14.

Chalmers, D., Davies, G. \& Monti, G. (2010). European Union Law, 2nd edition. Cambridge: Cambridge University Press.

Comissão Europeia (2015). Proposal for a Regulation of the European Parliament and of the Council on the European Border and Coast Guard, COM(2015) 671 final, Estrasburgo, 12 dezembro 2015 [Online], <https://ec.europa.eu/home-affairs/sites/homeaffairs/files/what-we-do/policies/securing-eu-borders/legal-documents/docs/regulation_on_the_european_border_and_coast_guard_en.pdf> (Acesso: 20 dezembro 2018).

- (2016a). Recomendação de 10 de fevereiro de 2016, C(2016) 871 final [Online], <https:// ec.europa.eu/home-affairs/sites/homeaffairs/files/what-we-do/policies/european-agenda-migration/proposal-implementation-package/docs/commission_recommendation_addressed_to_the_hellenic_republic_20160210_pt.pdf> (Acesso: 20 de dezembro de 2018).

- (2016b). Communication from the Commission to the European Parliament and the Council on the State of Play of Implementation of the Priority Actions under the European Agenda on Migration, Bruxelas, 10.2.2016 COM(2016) 85 final [Online], <https://ec.europa.eu/transparency/regdoc/rep/1/2016/EN/1-2016-85-EN-F1-1.PDF> (Acesso: 20 de dezembro de 2018).

- (2016c). Communication from the Commission to the European Parliament and the Council: Towards a reform of the Common European Asylum System and Enhancing Legal Avenues to Europe, Bruxelas, 6.4.2016, COM(2016) 197 final [Online], <https:// ec.europa.eu/transparency/regdoc/rep/1/2016/IT/1-2016-197-EN-F1-1.PDF> (Acesso: 20 de dezembro de 2018).

- (2016d). Evaluation of the Implementation of the Dublin III Regulation, Bruxelas, 18 de março de 2016 [Online], <https://ec.europa.eu/home-affairs/sites/homeaffairs/files/ what-we-do/policies/asylum/examination-of-applicants/docs/evaluation_of_the_ implementation_of_the_dublin_iii_regulation_en.pdf $>$ (Acesso: 20 de dezembro de 2018).

- (2016e). Proposal for a Regulation of the European Parliament and of the Council on standards for the qualification of third-country nationals or stateless persons as ben- 
eficiaries of international protection, COM (2016) 466 final, Bruxelas, 13 julho 2016 [Online], <https://ec.europa.eu/home-affairs/sites/homeaffairs/files/what-we-do/policies/european-agenda-migration/proposal-implementation-package/docs/20160713/ proposal_on_beneficiaries_of_international_protection_-_subsidiary_protection_eligibility_-_protection_granted_en.pdf> (Acesso: 20 dezembro de 2018).

- (2016f). Proposal for a Regulation of the European Parliament and of the Council establishing a common procedure for international protection in the Union, $\operatorname{COM}(2016)$ 467 final, Bruxelas, 13 julho 2016 [Online], <https:/ec.europa.eu/home-affairs/sites/ homeaffairs/files/what-we-do/policies/european-agenda-migration/proposal-implementation-package/docs/20160713/proposal_for_a_common_procedure_for_international_protection_in_the_union_en.pdf> (Acesso: 20 dezembro 2018).

- (2016g). Proposal for a Regulation of the European Parliament and of the Council on the European Union Agency for Asylum and repealing Regulation (EU) No 439/2010, $\operatorname{COM}(2016) 271$ final, Bruxelas, 4 maio 2016 [Online], <https:/ec.europa.eu/transparency/regdoc/rep/1/2016/IT/1-2016-271-EN-F1-1.PDF> (Acesso: 20 dezembro 2018).

- (2016h). Proposal for a Regulation of the European Parliament and of the Council establishing the criteria and mechanisms for determining the Member State responsible for examining an application for international protection lodged in one of the Member States by a third-country national or a stateless person (recast), COM(2016) 270 final, Bruxelas, 4 maio 2016 [Online], <https://ec.europa.eu/transparency/regdoc/ rep/1/2016/EN/1-2016-270-EN-F1-1.PDF> (Acesso: 20 dezembro 2018).

- (2016i). Proposal for a Regulation of the European Parliament and of the Council on the establishment of 'Eurodac' for the comparison of fingerprints for the effective application of [Regulation (EU) No 604/2013 (recast), COM(2016) 272 final, Bruxelas, 4 maio 2016 [Online], <https://ec.europa.eu/transparency/regdoc/rep/1/2016/EN/12016-272-EN-F1-1.PDF> (Acesso: 20 dezembro 2018).

- (2016j). Proposal for a Directive of the European Parliament and of the Council laying down standards for the reception of applicants for international protection (recast), COM(2016) 465 final, Bruxelas, 13 julho 2016 [Online], <https://ec.europa.eu/ home-affairs/sites/homeaffairs/files/what-we-do/policies/european-agenda-migration/proposal-implementation-package/docs/20160713/proposal_on_standards_ for_the_reception_of_applicants_for_international_protection_en.pdf $>$ (Acesso: 20 dezembro 2018).

- (20161). Communication from the Commission to the European Parliament, the European Council and the Council: Back to Schengen - A Roadmap, COM(2016) 120 final, 4 março 2016 [Online], <https://ec.europa.eu/home-affairs/sites/homeaffairs/files/what-we-do/policies/borders-and-visas/schengen/docs/communication-back-to-schengen-roadmap_en.pdf> (Acesso: 20 dezembro 2018).

- (2017a). White Paper on the Future of Europe, Bruxelas, 1 de março de 2017, COM(2017)2025 [Online], <https://ec.europa.eu/commission/sites/beta-political/files/white_paper_ on_the_future_of_europe_en.pdf> (Acesso: 20 de dezembro de 2018).

- (2017b). Reflection Paper on Harnessing Globalisation, Bruxelas, 10 de Maio 2017, $\operatorname{COM}(2017) 240$ [Online], <https://ec.europa.eu/commission/sites/beta-political/ files/reflection-paper-globalisation_en.pdf $>$ (Acesso: 20 de dezembro de 2018). 
Conselho Europeu (2018). European Council Conclusions, 28 June 2018 [Online], <https:// www.consilium.europa.eu/en/press/press-releases/2018/06/29/20180628-euco-conclusions-final/pdf> (Acesso: 20 dezembro 2018).

Dølvik, J. E. \& Martin, A., eds. (2017) European Social Models from Crisis to Crisis. Employment and Inequality in the Era of Monetary Integration. Oxford: Oxford University Press.

European Parliament Research Service (2016). Migration and Asylum [Online], <http://www. europarl.europa.eu/thinktank/infographics/migration/public/index.html?page=intro> (Acesso: 20 de dezembro de 2018).

Grimm, D. (2017). The Constitution of European Democracy. Oxford: Oxford University Press.

Hobbes, Th. (2012). Leviathan or The Matter, Forme and Power of a Common-Wealth Ecclesiasticall and Civil (1651), ed. by Noel Malcolm. Oxford: Clarendon Press of Oxford University Press.

Kant, I. (1991). Perpetual Peace: A Philosophical Sketch (1795). In Kant: Political Writings, 2nd edition, ed. by H.S. Reiss (pp. 93-130). Cambridge: Cambridge University Press.

Kassim, H., Menon, A. (2003) The principal-agent approach and the study of the European Union: promise unfulfilled? Journal of European Public Policy, 10(1), 121-139.

Majone, G. (1998). Europe's “Democratic Deficit”. The Question of Standards. European Law Journal, 4(1), 5-28.

- (2005). Dilemmas of European Integration. Oxford: Oxford University Press.

Menéndez, A.J. (2016). The Refugee Crisis: Between Human Tragedy and Symptom of the Structural Crisis of European Integration. European Law Journal, 22(4), 388-416.

Moravcsik, A. (1997). Taking Preferences Seriously: A Liberal Theory of International Politics. International Organization, 51(4), 513-53.

- (1998) The Choice for Europe: Social Purpose and State Power From Messina to Maastricht. Ithaca: Cornell University Press.

Olson, M. (1971). The Logic of Collective Action: Public Goods and the Theory of Groups, Revised ed. Cambridge, Mass.: Harvard University Press.

Phelan, W. (2012). What Is Sui Generis About the European Union? Costly International Cooperation in a Self-Contained Regime. International Studies Review, 14(3), 367-385.

Thielemann, E. (2018). Why Refuge Burden-Sharing Initiatives Fail: Public Goods, Free-Riding and Symbolic Solidarity in the EU. Journal of Common Market Studies, 56(1), 63-82.

Thielemann, E. and Armstrong, C. (2013). Understanding European asylum cooperation under the Schengen/Dublin System: a public goods framework. European Security, 22(2), 148-164.

V4Interior Ministers (2017). Joint Declaration of V4 Interior Ministers, Budapest, 5 October 2017 [Online], <http://www.visegradgroup.eu/calendar/selected-events-in-2017-170203/ joint-declaration-of-v4> (Acesso: 20 dezembro 2018).

Weber, M. (1946). Politics as Vocation (1918). In From Max Weber: Essays in Sociology, ed. by H.H. Gerth and C. Wright Mills (pp. 77-128). New York: Oxford University Press. 


\section{Sobre o autor}

GABRIELE DE ANGELIS conseguiu o doutoramento na Sant'Anna School of Advanced Studies (Pisa, Itália) e uma Grundständige Promotion na Ruprecht-Karls-Universität de Heidelberg (Alemanha). É um filósofo da política e trabalha como investigador na Universidade Nova de Lisboa. A sua pesquisa verte sobre a legitimidade política da União Económica e Monetária da União Europeia e, em geral, dos sistemas europeus de governança, na perspetiva das reformas discutidas ao nível comunitário. É autor de numerosas publicações que incluem artigos, monografias, organização de livros e números especiais de revistas internacionais sobre tópicos da legitimidade política em contextos nacionais e internacionais, e história do pensamento político.

\section{About the author}

GABRIELE DE ANGELIS obtained his doctorate at Sant'Anna School of Advanced Studies (Pisa, Italy) and a Grundständige Promotion at Ruprecht-Karls-Universität in Heidelberg (Germany). He is a philosopher of politics and works as a researcher at the NOVA University of Lisbon. His research sheds light on the political legitimacy of the European Union's Economic and Monetary Union and, in general, of European governance systems, taking into account the reforms discussed at Community level. He has authored numerous publications including articles, monographs, book organizations and special international magazine issues on topics of political legitimacy in national and international contexts, as well as the history of political thought. 